\title{
TRAUMATIC DISLOCATION OF THE HIP IN CHILDREN
}

\author{
C. M. OFFIERSKI
}

From the Hospital for Sick Children, Toronto

Thirty-three children with traumatic dislocation of the hip who had been treated at the Hospital for Sick Children between 1960 and 1977 were reviewed. The amount of trauma causing dislocation of the hip in younger children was less than that for older children. The most frequent complication was soft-tissue interposition which usually required a posterior arthrotomy to clear the interposed tissue. Less frequent complications included avascular necrosis, redislocation of the hip and an irreducible hip. Nineteen children were reviewed with an average follow-up time of 10 years. Clinical examination indicated that 84 per cent of these hips were normal but the radiographs showed that 47 per cent of the dislocated hips had a coxa magna of two millimetres or more. There was no correlation between the development of coxa magna and the clinical result.

Traumatic dislocation of the hip is an uncommon injury in children and reviews of this subject have been limited to case reports (Freeman 1961; Haliburton, Brockenshire and Barber 1961; Piggot 1961) or combined studies from several clinics (Glass and Powell 1961; Funk 1962; Pennsylvania Orthopaedic Society 1968; Pearson and Mann 1973). This review of 33 traumatic dislocations of the hip determines the important points in treatment, the complications of this injury, and the effect of traumatic dislocation on the subsequent development of the hip.

\section{METHOD}

A chart review of the 33 patients was used to relate the distribution of age, the severity of the injury causing dislocation, the presence of associated injuries, the time before reduction and the method of treatment.

The trauma causing dislocation was graded into three types: mild -injury caused by running, tripping or falling; moderate - injury as a result of excessive speed (cycling or skiing) or excessive force (football); severe-injury caused by a high energy impact or crushing. The children were then examined to assess the function and development of the hip. A clinical assessment was made for symptoms, range of movement, function and disability of the hips.

Radiographs of the hip were taken in both the anteroposterior and frog-leg positions and the presence of coxa magna, irregularity of the femoral head and the presence of arthritic changes in the hip recorded.

\section{RESULTS}

The ratio of boys to girls in this group of 33 children was $2: 1$, with an equal distribution of right and left hips. The age range was 1.5 to 14 years, with two-thirds of the patients aged six or under.
Half the children aged 10 or less had dislocated hips resulting from mild trauma. The dislocated hips in children over the age of 10 were caused by moderate or severe trauma (Fig. 1).

Associated injuries were found in the 10 children with severe trauma. These included five head injuries; and six associated fractures of the pelvis or of other bones. There were no fractures of the acetabulum or femoral neck. The dislocations were posterior in 29

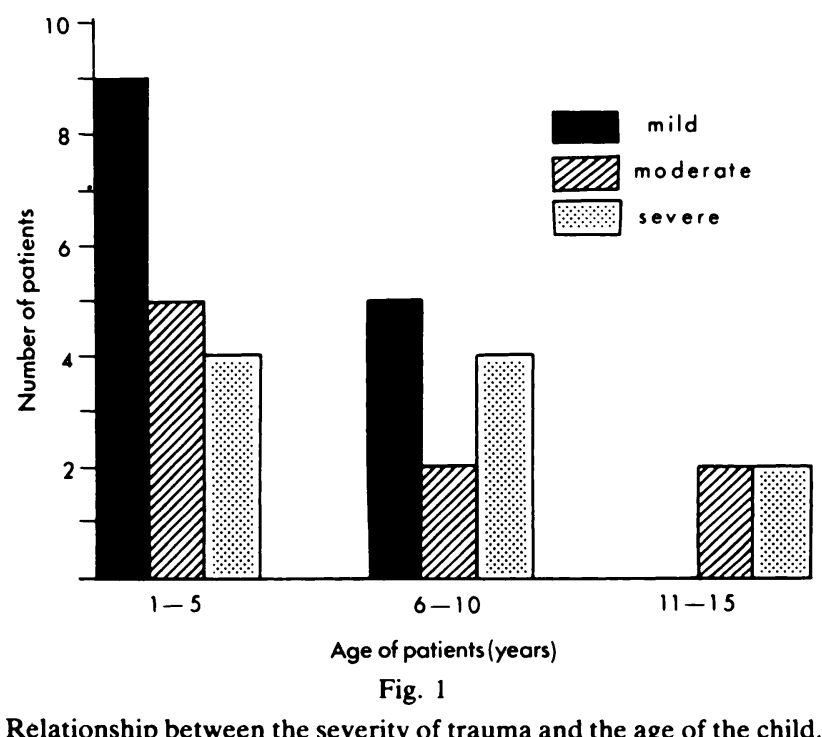

children, anterior in two and undetermined in two. The latter two reduced spontaneously. In 30 children closed reduction was performed. One hip which had been diagnosed late was irreducible by closed reduction at three months and subsequently required open reduction three years later.

C. M. Offierski, MD, Chief Resident, Division of Orthopaedic Surgery, The Hospital for Sick Children, 555 University Avenue, Toronto, Ontario, Canada M5G 1 X8.

(1) 1981 British Editorial Society of Bone and Joint Surgery 0301-620X/81/2041-0194\$2.00 


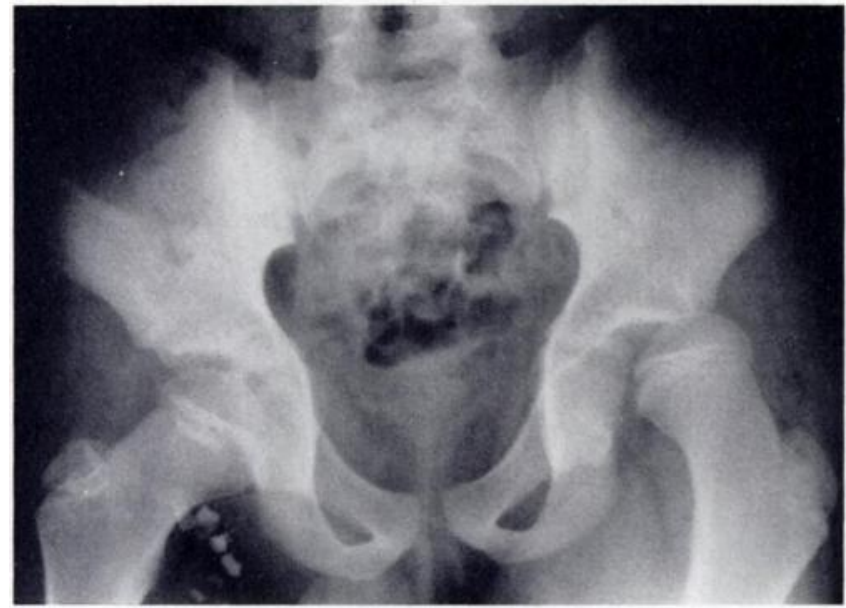

Fig. 2

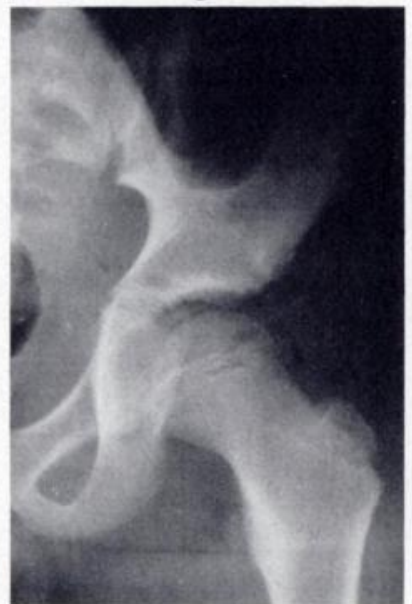

Fig. 4

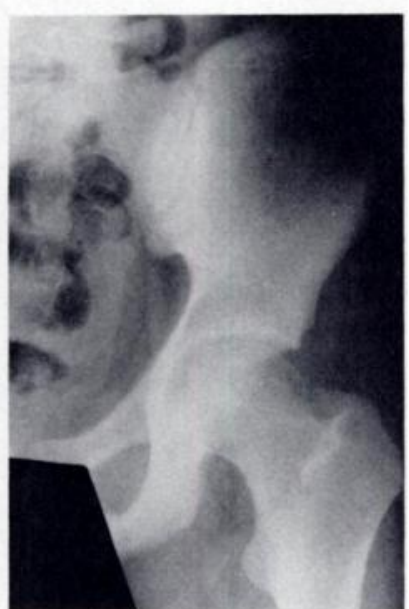

Fig. 5

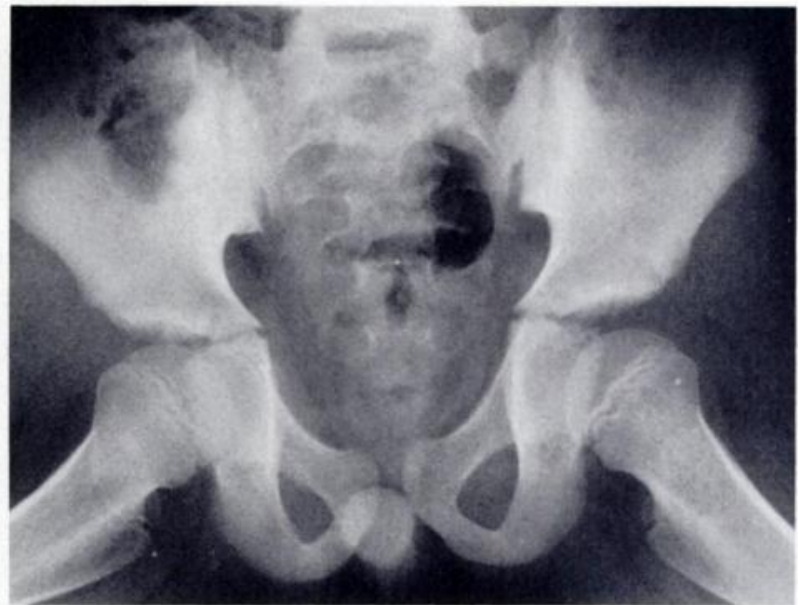

Fig. 3

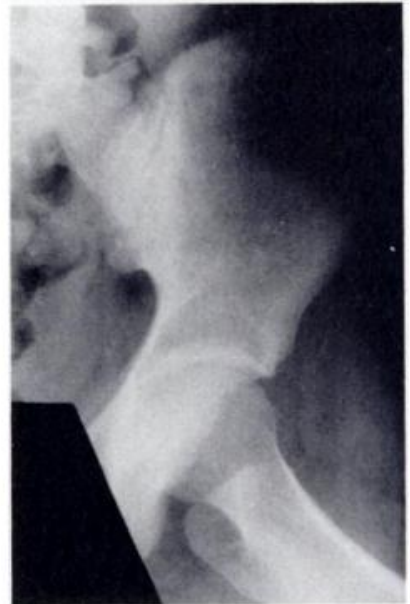

Fig. 6

Radiographs of the left hip of a 10-year-old boy. Figure 2-Dislocation of the left hip caused by moderate trauma. Figure 3-Closed reduction carried out six hours after injury. An increase in the medial joint space is shown. Figure 4-Reduction after arthrotomy and removal of the interposed tissue two days after the initial injury. Figure 5-Radiograph taken in the anteroposterior position six years after dislocation. Figure 6-Radiograph taken in the frog-leg position six years after dislocation.

The time before reduction was less than six hours in 25 children, between seven and 12 hours in two and between 12 and 24 hours in another two. Diagnosis was made late in two children with severe head injuries and with pelvic fractures indicating trauma around the hip at the time of injury. Closed reduction was successful at three weeks in one hip but reduction at three months failed in the other.

In 27 patients the hips were immobilised for between four and six weeks using a hip spica, three others were treated by traction, and another three had no treatment.

Complications. Nine children developed complications as a result of traumatic dislocation of the hip.

Soft-tissue interposition. The medial joint space increased in five children as a result of soft-tissue interposition. Treatment with traction was successful in one child and the other four underwent arthrotomy by the posterior approach for removal of the interposed tissue (Figs 2-6). In all four children part of the posterior acetabular labrum had folded into the hip so preventing proper reduction.
Avascular necrosis. One child who sustained a severe injury had a compound anterior dislocation which was reduced 13 hours later. This patient developed avascular necrosis and came to fusion.

Recurrent dislocation. Another child had two recurrent dislocations. The first was treated in a hip spica for a further six weeks. An arthrogram taken after the third dislocation demonstrated a posterior leak, which disappeared after three more months in a hip spica. She has had no further recurrences.

Delayed diagnosis. Two children had severe head injuries and were found to have a dislocated hip three weeks and three months after injury. The former was reduced at three weeks, but stiffness was reported at the follow-up. The other hip was irreducible at three months and subsequently came to fusion three years later.

Follow-up. Nineteen of the 33 children were reviewed. The others were lost to follow-up and one died of associated injuries. The follow-up ranged from 3 to 20 years with an average of 10 years. Nine of the 19 children were skeletally mature. After clinical examination the hip was classed as normal in 16 children, one 
child had a stiff hip and another two had fused hips.

Radiographic assessment of 17 children, one of whom had an irregular femoral head and coxa magna, showed the hip to be normal in eight, the presence of coxa magna in nine, and an irregular femoral head in one other. There was no radiographic evidence of degenerative changes. Fifty-three per cent of the children reviewed had coxa magna of two millimetres or more in the affected hip (Fig. 7). Most of the hips with coxa magna had complications associated with the disloca-

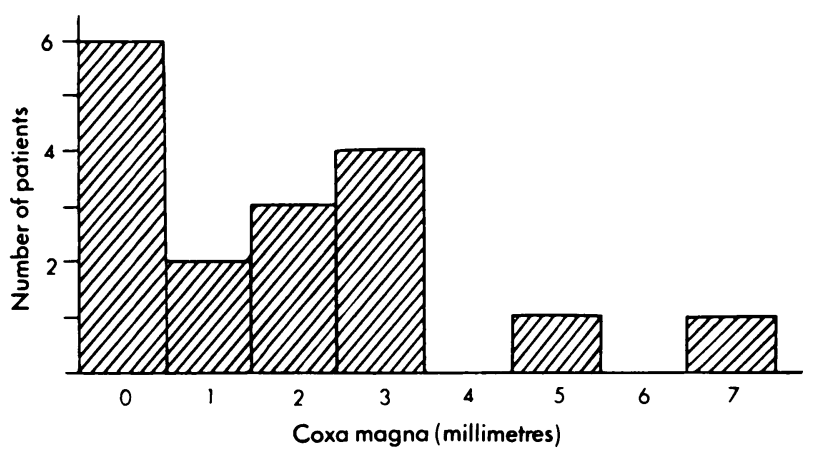

Fig. 7

The incidence of coxa magna at follow-up.

tion; but only one was clinically abnormal. A bone scan performed shortly after dislocation showed a marked "hot-spot" involving the whole of the proximal end of the femur (Fig. 8). Radiographs of the nine children who had become skeletally mature showed that the acetabulum had grown to accommodate the enlarged femoral head. There were no cases of arthritis.

\section{DISCUSSION}

The age distribution, sex ratio and type of dislocation in the 33 children reviewed are comparable with the results in similar studies (Pearson and Mann 1973). As reported by Glass and Powell (1961) and Funk (1962), the hip will dislocate with less trauma in the younger age group. Rališ and McKibbin (1973) have previously shown that the head of the femur becomes increasingly covered by the acetabulum during development and is more stable with maturity. Ninety per cent of the dislocated hips in this series were reduced within 12 hours. Three of the four hips reduced after 12 hours did poorly. There were no instances in this series of associated acetabular or femoral neck fractures. This contrasts with dislocations in the adult in which 75 per cent have an associated acetabular fracture (Thompson and Epstein 1951).

The most common complication was soft-tissue interposition with an incidence of 15 per cent. It may impair congruent reduction and can be easily overlooked. An increased medial joint space after the reduction of a traumatic dislocation is caused by soft-tissue interposition within the joint. It is therefore important to recognise this complication and to remove the interposed tissue.

The incidence of avascular necrosis in this series is three per cent. This complication has been discussed in previous case reports of traumatic dislocation of the hip which give the impression that this is a frequent complication with an incidence around 10 per cent (Glass and Powell 1961). However, large series reported by Funk (1962) and the Pennsylvania Orthopaedic Society (1968) have an incidence of 10 per cent or less. A review of the literature disclosed that three-quarters of the patients with avascular necrosis had reduction delayed by more than 24 hours and that the others received severe trauma directly to the hip. When the hip is dislocated by minor trauma and is promptly reduced, avascular necrosis is an uncommon complication. There are no neurological injuries associated with posterior dislocation in this series although Pearson and Mann (1973) reported the incidence of sciatic nerve palsy to be 20 per cent.

In conclusion, 85 per cent of the children had normal hip function after a traumatic dislocation. Two patients came to fusion as a result of complications, and

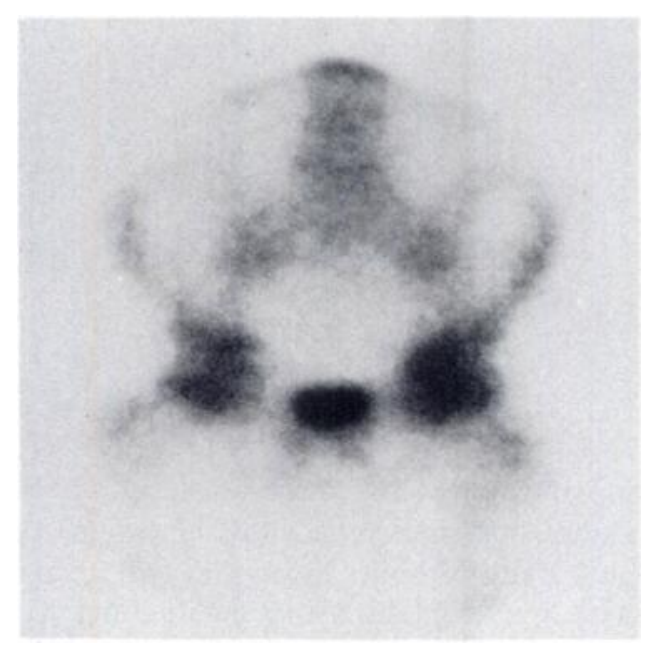

Fig. 8

Bone scan taken after closed reduction of traumatic dislocation of the left hip.

one patient had a stiff hip due to a delayed reduction. Radiographs of these hips at follow-up, to study the effect of dislocation on the development of the hip, showed that 47 per cent had coxa magna. The development of coxa magna did not seem to be related to age, the severity of trauma, the time before reduction or the method of treatment and did not affect the clinical outcome. However, Glass and Powell (1961) found coxa magna in only 13 per cent of their patients. The aetiology of coxa magna is probably a reactive hyperaemia secondary to the extensive soft-tissue injury.

I would like to express my appreciation and thanks to Dr Mercer Rang for his help and guidance with this paper. 


\section{REFERENCES}

Freeman GE Jr. Traumatic dislocation of the hip in children. $J$ Bone Joint Surg [Am] 1961;43-A:401-6.

Funk FJ Jr. Traumatic dislocation of the hip in children. J Bone Joint Surg [Am] 1962;44-A:1135-45.

Glass A, Powell HDW. Traumatic dislocation of the hip in children. J Bone Joint Surg [Br] 1961;43-B:29-37.

Haliburton RA, Brockenshire FA, Barber JR. Avascular necrosis of the femoral capital epiphysis after traumatic dislocation of the hip in children. J Bone Joint Surg $[B r] 1961 ; 43-B: 43-6$.

Pearson DE, Mann RJ. Traumatic hip dislocation in children. Clin Orthop 1973;92:189-94

Pennsylvania Orthopaedic Society, Scientific Research Committee. Traumatic dislocation of the hip joint in children. J Bone Joint Surg [Am] 1968;50-A:79-88.

Piggot J. Traumatic dislocation of the hip in childhood. J Bone Joint Surg [Br] 1961;43-B:38-42.

Raližs Z, McKibbin B. Changes in the shape of the human hip joint during its development and their relation to its stability.J Bone Joint Surg [Br] 1973;55-B:780-5.

Thompson VP, Epstein HC. Traumatic dislocation of the hip: a survey of two hundred and four cases covering a period of twenty-one years. $J$ Bone Joint Surg [Am]1951;33-A:746-77. 